\title{
NEOGLOBALIZACIÓN Y CAMBIO DEMOGRÁFICO
}

\section{Luis Héctor González Mendoza ${ }^{1}$}

\section{Resumen}

En el presente escrito titulado: Neoglobalización y Cambio Demográfico, planteo la hipótesis de que la globalización evoluciona y reproduce desigualdades, no sólo en las naciones en vías de desarrollo, sino en las sociedades desarrolladas, proyectando una especie nueva globalización, que al parecer interviene no sólo en procesos económicos, sino demográficos, dando paso a sociedades en situaciones de envejecimiento.

Palabras clave: Neoglobalización, cambio demográfico, desigualdades, jóvenes y viejos.

\section{LA NEOGLOBALIZACIÓN}

Durante algún tiempo la globalización fue identificada como efecto de un renovado capitalismo, asimismo, reconocida por la mejora en el desarrollo industrial, comercial y de servicios, pero, sobre todo referida a la producción y uso de tecnologías a escalas mundiales, posteriormente se sumaron estudios, marcando lo multidimensional y claroscuros de aquella, irónicamente, en la actualidad se crítica, desde las sociedades desarrolladas.

Las recientes iniciativas del Reino Unido y su salida de la Unión Europea, el Brexit, así como, las delirantes declaraciones de Trump respecto al papel de los Estados Unidos en el desarrollo y crecimiento económico mundial, el hecho de la reinstalación de empresas trasnacionales en su propio territorio y el retiro de los Estados Unidos del Acuerdo de Paris sobre el cambio climático, permiten observar un reacomodo de las sociedades desarrolladas, dando paso a una especie de neoglobalización.

Sygmunt Bauman, sociólogo de origen polaco, nos demostró que con el empleo de la palabra globalización, se hace referencia a muchos significados, ya que desde hace tiempo, es una expresión de manejo cotidiano, de tal forma que se relaciona con todo y explica poco, que implica causas y efectos de vida diaria, a su vez identifica procesos que irremediablemente afectan a todo el mundo, e incluso puede plantear posiciones ideológicas extremas, y aún más, es una palabra que se desgasta para el cometido de explicación original.

\footnotetext{
${ }^{1}$ Doctor en Sociología UNAM. Diplomado en Psicoanálisis y Cultura UNAM. Especialidad en Historia de México, UPN. Tutor en la Licenciatura de Educación e Innovación Pedagógica Plan Modular a Distancia de la UPN. Docente en la Licenciatura de Psicología de la Educación de la UPN.E-mail: lhector@upn.mx
} 
(Bauman, 1997)

Por su parte, el connotado sociólogo británico, Anthony Giddens, marca el desenvolvimiento de la globalización e identifica a la sociedad estadounidense como la fuente de la globalización. "Está dirigida por Occidente, lleva la fuerte impronta del poder político y económico estadounidense y es altamente desigual en sus consecuencias." (Giddens, 2000)

A su vez, Ulrich Beck, en un análisis sociológico más profundo, señala que en Alemania la globalización se percibe negativamente, porque las trasnacionales ubicadas en aquel país se trasladan a otros lugares en donde la mano de obra es más barata, o las ventajas fiscales son mayores, o bien otro conjunto de incentivos que favorecen la migración de empresas, como resultado se nota una reducción de puestos de trabajo en la sociedad germana.

Así resulta que la globalización se identifica por los beneficios económicos que reportan las empresas trasnacionales. A su vez, el sociólogo alemán, advierte que la globalización se cierne como amenaza en países con cierto grado de nacionalismo y con políticas de bienestar, entre los que se encuentran: Francia, Austria, Suiza, Italia y, por supuesto, Alemania.

Resulta que, para algunas sociedades europeas, el desenvolvimiento de la globalización agudiza la disyuntiva entre las políticas económicas de ésta y las políticas sociales de los estados de bienestar. Incluso, se señala que la globalización influye en la homogeneidad social, ya que ésta conlleva expresiones y experiencias propias de las empresas trasnacionales y de los países de origen, por supuesto que las inversiones extranjeras, los mecanismos de publicidad de los estilos de vida globales, y la inmigración laboral, social y cultural son las experiencias que se establecen no sólo en Alemania, sino en gran parte de Europa. (Beck, 1997)

Si se continúan revisando los planteamientos sociológicos de Beck, se mira que la globalización se interpreta de manera multidimensional, en consecuencia, de forma paradojal, porque las quejas expresadas en países europeos no pueden ignorar que muchas empresas trasnacionales son de origen europeo y que participan directamente en la globalización.

Con el análisis realizado por el sociólogo alemán, la globalización se mira como una compleja red de relaciones capitalistas que involucran no sólo actores internacionales y trasnacionales, sino de Estados nacionales, que con relativas diferencias apuntan hacia la consolidación y apertura de mercados, estimulando el consumo de productos y servicios globalizados.

A la vez se puede observar que junto con la globalización se materializan situaciones ideológicas, sociales, comunicacionales y territoriales identificadas con términos nuevos, tales y como son: el globalismo, la globalidad y la glocalidad.

La globalización conlleva una ideología, es el globalismo, esta ideología que puede ser interpretada como una relación imaginaria para con las condiciones materiales de existencia, al grado de tomar forma en los 
innumerables discursos que expresan los actores de la globalización, representantes que formulan supuestos con los cuales resaltan los beneficios del nuevo modelo económico, hablan acerca de lo provechoso que resultaría abrir los mercados mediante el libre cambio y circulación de mercancías y servicios, impulsar la flexibilidad en la contratación de la fuerza de trabajo, y la pertinencia de eliminar el proteccionismo para profundizar económicamente la globalización.

Por su parte, la globalidad, significa manifestaciones sociales y comunicacionales que muy bien podríamos asociar como inherentes a la era de la información y, que difícilmente los actores de la globalización pueden contener, esto significa que una gran cantidad de flujos humanos y de información traspasan continuamente las fronteras nacionales.

En el primero de los casos, resulta que muchas personas originarias de sociedades en desarrollo se mueven hacia sociedades desarrolladas, generalmente en busca de trabajo, son flujos de población que difícilmente pueden contener los gobiernos locales, por ejemplo, en nuestro caso, se identifica población mexicana que permanentemente emigra hacia Estados Unidos, lo cual prácticamente es un mal endémico y, qué decir de la migración latinoamericana y africana hacia Europa, asimismo, las sociedades receptoras intentan con muchas dificultades detener o regular los flujos de población.

En contraste se observa mucha población que se traslada de sociedades desarrolladas hacía sociedades en desarrollo y viceversa, son personas que viajan como turistas. También se cuentan numerosos empleados de corporaciones trasnacionales y de instituciones internacionales que debido a los procesos económicos, sociales y políticos globalizados viajan a través de diferentes países del mundo.

Asimismo, es posible observar personas, notoriamente jóvenes, de distintas regiones del mundo reaccionando ante las reuniones de los representantes de la globalización y se agrupan para expresar el malestar provocado por ésta, generalmente lo hacen a través de manifestaciones in situ, personas en grupos a quienes denominan "globalifóbicos".

También se identifican caravanas que denuncian los riesgos que implican las corporaciones relacionadas con la energía nuclear, el desarrollo bioquímico y petrolero, son manifestaciones en contra de las compañías involucradas en derramamientos de petróleo, las industrias vinculadas con la matanza de focas, la caza de ballenas, etcétera, son una gran variedad de corrientes y movimientos sociales que emergen denunciando los riesgos de la globalización y que son difíciles de contener por los gobiernos locales.

Y qué decir del movimiento M 15 o "Indignados" de España. La movilización estudiantil chilena, que esporádicamente se expresa en contra de las políticas educativas neoliberales. En el caso mexicano Todos Somos 123 y la trágica experiencia de los 43 de Ayotzinapa, esta última, si bien es cierto, no implicaba una manifestación en contra de la globalización, la resonancia del hecho se conoce debido a la comunicación globalizada o 
globalidad comunicacional.

La globalidad también significa enormes flujos de información debido a la existencia de medios de comunicación no sólo tradicionales, sino nuevos, lo que a su vez representaría la producción, circulación y consumo de una gran gama de imágenes, sonidos y temáticas, junto con los diversos y cada vez más modernos instrumentos de comunicación, que muy probablemente están reconfigurando los estilos de vida de la población en general y de los jóvenes en particular.

Un reciente hecho que se sumaría a la globalidad podría ser el fenómeno wikileaks, que literalmente significa fuga, goteo o filtración, se trata de información clasificada. Se sabe que, wikileaks, era una organización mediática internacional, que mantuvo un sitio web con informes anónimos y documentos filtrados, que permitieron conocer e informar la actividad exterior del gobierno de Estados Unidos y de algunos países globalizados. Así el lado oscuro y oculto de la diplomacia se puso de manifiesto con las crudas palabras de los funcionarios del poder de los gobiernos hegemónicos, que al parecer, les tiene sin cuidado la democracia y los intereses ciudadanos de los cuales suponen emerger y representar.

Por su parte, la glocalidad se refiere al hecho de que la globalización en su condición multidimensional se relaciona prácticamente con todo el espacio mundial, incluyendo no sólo las ciudades de las sociedades desarrolladas y en vías de desarrollo, sino los pequeños poblados de éstos, en donde los patrones de comportamiento de las poblaciones modifican sus hábitos y a la vez mantienen costumbres locales.

La globalización, el globalismo y la globalidad implican no sólo relaciones económicas, ideológicas, sociales y de información que se manifiestan y consumen internacionalmente en zonas urbanas desarrolladas y en desarrollo, sino que es posible advertir que todo ello se mezcla y se asume con cierta dosis de originalidad y resistencia en asentamientos locales.

Lo expresado es parte del análisis sociológico realizado desde la vieja Europa, que llama poderosamente la atención, porque se critica la globalización como algo externo, cuando esa región también forman parte de ésta, son sociedades desarrolladas que forman bloques económicos mediante grupos de empresas trasnacionales que se desenvuelven a escala mundial, del mismo modo son parte directiva de instituciones de tipo internacional y algunos de sus gobiernos forman parte activa de las reformas neoliberales.

Ahora bien, en la misma línea de identificación de la globalización como algo externo y en base al desarrollo del capitalismo no sólo de la sociedad estadunidense, sino de un conjunto de nueve sociedades globalizadas y centralizadas, es posible registrar estudios del desarrollo de capitalismo desde el marco de las sociedades.

Samir Amin ha dedicado gran parte de su quehacer intelectual al estudio de tales sociedades, así como al análisis del papel del Estado en éstas y él identifica que el capitalismo se profundiza en la era de la globalización, 
señalando que el sistema capitalista mundial muestra nuevos signos, entre los que destaca: 1) el desgaste del Estado-nación para impulsar la reproducción y acumulación de capital; y 2) las nuevas articulaciones económicas del centro industrial, e incluso, postindustrial hacía regiones periféricas industriales y no. (Samir, 1999)

De acuerdo a los planteamientos de Samir Amín, en la era de la globalización, la acumulación y reproducción del capital y del trabajo, se desarrolla a través de fronteras económicas altamente flexibles y, al parecer se desarrollan por fuera de los límites del Estado-nación. Así las sociedades que mantienen y estimulan la globalización, forman y refuerzan un centro industrializado, e incluso podríamos señalar la existencia de un eje postindustrial, que frena la industrialización de la periferia. En resumen, para Samir Amin el desarrollo industrial y posindustrial de las sociedades centrales se acelera, en cambio, el de las sociedades periféricas se frena.

Para sustentar tal afirmación, el autor señala la existencia de cinco monopolios con los cuales se apuntala la reproducción y la acumulación capitalista, que a su vez favorece a las sociedades desarrolladas y centrales: a) el monopolio tecnológico que se desarrolla fundamentalmente en países centrales; b) el monopolio de los mercados financieros mundiales que se realiza a través de los capitales centrales; c) el acceso monopolista a los recursos naturales del planeta; d) el monopolio de los medios de comunicación; y e) el monopolio de las armas de destrucción masiva.

A juicio de Samir Amin, estos son privilegios con los cuales los países centrales refuerzan su propio desarrollo, por supuesto, que en detrimento del desenvolvimiento de las sociedades periféricas, aún más, para los primeros significa posiciones de fuerza que matizan con la idea de la interdependencia, evidentemente, dejando de lado las articulaciones de la desigualdad o asimetría y, en todo caso, señalando las ventajas del intercambio económico que anuncia la globalización, es la presencia y uso de un privilegio y monopolio de medios de comunicación por parte de las sociedades centrales.

Con la globalización se observa un reacomodamiento del centro y la periferia, que si lo asociamos a las ideas de la dependencia y el subdesarrollo se continúa identificando un reducido número de sociedades centrales y desarrolladas frente a un gran conjunto de sociedades periféricas y subdesarrolladas, destacando ahora un reajuste, en donde la sociedad norteamericana domina y readapta las relaciones de la globalización para con sociedades situadas en el resto del mundo.

Si miramos a la globalización con los trazos del desarrollo capitalista central y del subdesarrollo capitalista periférico, podríamos observar un cuadro en el cual aparece un centro con muy pocas sociedades desarrolladas y en franca globalización, del mismo modo y alrededor del centro, o sea en la periferia, observaríamos un amplio espectro de sociedades subdesarrolladas.

La globalización central estaría ubicada en tres bloques. En América del norte: Estados Unidos y Canadá. En Europa: Alemania, Francia, Inglaterra, Italia, y el singular papel más que económico, político de Rusia. Y en el 
caso del bloque asiático: Japón. Con el claro despunte de la economía china. En cambio, la globalización periférica, estaría compuesta por una cantidad de aproximadamente ciento noventa países que muestran dificultades en el desarrollo y crecimiento industrial.

En resumen, el centro de la globalización, sería el llamado "Grupo de los Ocho" que mantiene a igual número de sociedades con economías centrales y globalizadas, con una periferia compuesta de más más de cien sociedades que marchan con dificultades hacia la globalización, se observa que en un afán de inclusión, este pequeño grupo abre sus puertas de otras naciones denominadas en vías de desarrollo, con lo cual el conjunto de países se cuenta en veinte, aun así deja fuera a poco más de ochenta sociedades.

Actualmente la globalización confronta un reacomodo de algunas sociedades desarrolladas, lo cual, quizá nos permitan mirar un relativo movimiento de fronteras físicas y jurídicas, pero difícilmente se podrían cerrar los límites industriales y comerciales, por ejemplo, la posición del Reino Unido ante la Unión Europea, el llamado Brexit y de los amagos de Trump no sólo respecto al Tratado de Libre Comercio de Norte América, sino los reclamos hechos a Alemania y otros países europeos, parecen ser iniciativas políticas marcadas de cierto protagonismo, que perfilan una relativa recomposición de la globalización y por ende un impacto diferenciado en las sociedades industriales y desarrolladas, frente a las sociedades en vías de desarrollo industrial, hechos que son recientes, por lo mismo requieren de espera para conocer posibles formas de desarrollo.

\section{EL CAMBIO DEMOGRÁFICO}

Desde hace ya algún tiempo, el desarrollo demográfico nos permite observar que a escala mundial el crecimiento poblacional se incrementa.

"Los primeros 1000 millones de habitantes se alcanzaron en 1850, los siguientes 1000 llegaron menos de un siglo más tarde, en 1930. Los 3000 millones se registraron en 1960. El ritmo de crecimiento demográfico se mantuvo acelerado y los 4000 millones se alcanzaron en 1974. En 1987 la población del mundo llegó a 5000 millones y en 1999 se estimaron 6000 millones de personas." (García, 2010)

Entre 1960 y 1965, llamó poderosamente la atención el acelerado incremento mundial de la población, dando paso a la expresión: explosión demográfica. Y de no haber sido por las políticas orientadas hacia el control de la natalidad, la llamada explosión demográfica se hubiese disparado aún más. No obstante, el desarrollo demográfico a escala mundial siguió aumentando, sólo que con ciertas variaciones. Junto al control de la natalidad, se logró descender la mortalidad, y se estimuló el desarrollo tecnológico sanitario, que en su conjunto permitió el aumento de la esperanza de vida, permitiendo al ser humano alcanzar mayor tiempo de vida.

De manera reciente la revista National Geographic en español, trató el asunto del crecimiento poblacional, señalando que desde hace trescientos años se dio inicio a la preocupación y debate, acerca de este y la producción 
alimentaria, asimismo se indica que la reflexión y polémica se ha diversificado, la revista, muy a su estilo, muestra reportajes e ilustraciones que permiten apreciar información e imágenes acerca de la evolución y distribución geográfica de la población, que para este año representa la cantidad de 7,000 millones de habitantes en la tierra; del mismo modo señalan que continuaran abordando el tema y se plantean las siguientes preguntas: ¿Cuál será el crecimiento real de la población? ¿Cuál será el aspecto del planeta en el 2045?

Son preguntas cuyas respuestas no pueden ser dadas mediante la revisión del desarrollo demográfico, sino más bien, con el estudio de la transición demográfica, o sea el análisis de sociedades que le han dado un giro a las condiciones de alta mortalidad y natalidad, reduciendo los niveles de éstas. Al respecto, la expresión transición demográfica, la entenderemos con el término cambio demográfico, ya que es un concepto sociológicamente más acorde para aproximarnos al estudio las actuales sociedades.

Como ya se mencionó, a escala mundial, el desarrollo poblacional denota un crecimiento, que alcanza la cantidad de 7,000 millones de habitantes, producto de un cambio demográfico en el cual se observa una disminución de la natalidad, la mortalidad, y un progresivo aumento de la esperanza de vida de las personas, lo cual se traduce en menos nacimientos de niños, una baja en el número de jóvenes, más adultos, y un acrecentamiento de personas viejas.

En la primera década del siglo XXI, se nota la cantidad de 1200 millones de jóvenes de 15 a 24 años de edad. Mientras que se registran 506 millones de personas con 65 años o más. En términos demográficos se menciona el llamado bono demográfico, que significa una relación favorable entre las poblaciones en edades laborales (entre 15 y 64 años) y la población económicamente dependiente (menores de 15 y mayores de 64), del mismo modo se estima que la población mundial se halla en tal momento de oportunidad, ya que hacía el 2030 empezará a declinar, cuando precisamente la población de 64 años acelere su crecimiento. (Hernández, 2010)

Si atendemos al hecho de que los jóvenes de hoy, son los viejos del mañana, y que son jóvenes que se distribuyen en un $16 \%$ en sociedades desarrolladas, y el $84 \%$ restante en sociedades en desarrollo, podríamos indicar que las condiciones y manifestaciones del cambio demográfico se aprecian a escala mundial, y regionalmente se distinguen notables diferencias, grosso modo, se identifican: 1) Sociedades desarrolladas en las cuales ya escasean niños y jóvenes, son conglomerados sociales en los cuales la natalidad y la mortalidad muestran un notable descenso, provocando un progresivo aumento en el tamaño de la población adulta y mayor, a la vez, su envejecimiento, aunque cuentan recursos para paliar tal situación; 2) Sociedades no desarrolladas en las cuales la población infantil y juvenil aunque menor que en otras épocas aún se mantiene en crecimiento y, paralelamente se suman más adultos y ancianos, lo que permite observar sociedades, que con menos recursos, también avanzan hacia el envejecimiento.

El cambio demográfico conlleva múltiples transformaciones en la trayectoria de desarrollo y vida de los 
jóvenes y los viejos, por ejemplo, cambios en las formas de vida familiar, de empleo, de educación, y de salud. Si notamos las trayectorias de desarrollo social y de vida personal, distinguimos épocas de dependencia, autonomía y responsabilidad individual, familiar y social, que se miran alteradas por el desarrollo de la globalización.

En el marco de la sociedad la trayectoria de desarrollo y vida personal, es una especie de círculo, ya que inicia con la dependencia infantil, sigue con la autonomía juvenil, continúa con la responsabilidad adulta, culminando con la dependencia de la vejez.

Si observamos que todo nuevo miembro de la sociedad es un individuo que nace en familia, podemos ver que el nuevo ser requiere de trato y depende de los adultos, quienes a su vez con cierto grado de autonomía y responsabilidad se hacen cargo del nuevo miembro de una nueva generación. Si continuamos observando la trayectoria de desarrollo y vida personal, el ser miembro de las nuevas generaciones implica alcanzar cierta autonomía familiar, así como la adquisición de responsabilidades sociales. Por supuesto que la generación adulta avanza en la trayectoria de desarrollo y vida personal, alcanzando edades, en las cuales los estragos propios del envejecimiento implican el apoyo familiar, o bien hospitalario, e incluso el de asilos, con lo cual el trayecto de desarrollo y vida personal implica dependencia.

La responsabilidad de generaciones adultas para la socialización y cuidado de las generaciones infantiles y juveniles es algo común. Del mismo modo, las generaciones viejas, dependen de la atención y cuidado de sus familiares. En la actualidad se observa que junto con la disminución de tasas de natalidad, mortalidad y el incremento paulatino de la esperanza de vida, los jóvenes alargan su estancia en los hogares familiares, ya sea, por dificultades para obtener empleo, o bien porque extienden el tiempo de estudio, lo notable es que muchos jóvenes se mantienen durante más tiempo en el hogar paterno, y pensamos que muchos de estos jóvenes son los viejos del mañana, a los cuales el tiempo depara un nuevo horizonte de desarrollo y vida personal.

En el caso del empleo, es la vía más importante y usual para satisfacer necesidades individuales e incluso familiares, además es un medio para mantenerse activamente productivo e independiente, también ofrece satisfacciones y logros personales y sociales, por supuesto obtener y mantener un empleo significa que implica no sólo estudios y constante actualización, sino condiciones adecuadas de salud. Sin embargo, los jóvenes se encuentran frente a un empleo cada vez más globalizado, que exige alta especialización y experiencia profesional. Por supuesto que el mercado laboral se globaliza y cambia, ya que a los empleadores no sólo les convienen los trabajadores con conocimientos adquiridos escolarmente, sino que piden experiencia en habilidades de comunicación, trabajo en equipo y negociación, e incluso actitudes y estilos de vida acordes al concepto e imagen de las empresas.

Los sistemas escolares a su vez, experimentan la reducción del gasto social en la educación, aun así, se ensayan reformas y adecuaciones para colocar a sus egresados en los tradicionales y nuevos segmentos de un 
mercado laboral que evoluciona y se transforma globalmente.

Por su parte, los servicios de salud, tienden cada vez más hacía la privatización, de tal manera que la salud de la población es algo que se individualiza afectando los ingresos de los trabajadores, por supuesto que, si la salud individual del empleado sufre quebrantos, se afecta no sólo individual, sino familiar y socialmente.

Como ya se mencionó, el cambio demográfico anuncia múltiples transformaciones en la trayectoria de desarrollo y vida de los jóvenes de hoy, que son los viejos del futuro y, valdría la pena preguntarse: ¿Qué significa ser joven? Y ¿Qué significa ser viejo?

Joven, juventud y juvenil aluden de manera indistinta a una etapa del desarrollo humano irrepetible y relativamente corto, esto último si consideramos el criterio etario del ser joven 15 a 24 años de edad: ¡Tan sólo se es joven durante 9 años! Si definimos de manera formal, veremos que con el término joven es posible individualizar y registrar una edad personal que se sitúa entre las fronteras de ser infante y ser adulto; con la expresión juventud reconocemos colectivos de personas de poca edad, cuyas manifestaciones más visibles son el movimiento, la energía y el vigor; y con la palabra juvenil identificamos actitudes propias del joven y de la juventud, tales y como: la alegría, la vivacidad, la frescura y la espontaneidad.

Con este tipo de aproximaciones percibimos que las definiciones del ser joven en la actualidad son relativas, sobre todo en sociedades en donde fluye la migración de manera constante, tales son los casos, de varios países europeos y de la sociedad estadounidense. Con las definiciones formales podemos pensar que los jóvenes se manifiestan de manera natural a través del movimiento, la espontaneidad y la alegría, lo cual en cierto sentido es verdad. Sin embargo, en la cotidianeidad observamos la presencia social de grupos de jóvenes que no exteriorizan el movimiento, la espontaneidad y la alegría como rasgos predominantes, quizá, porque sus situaciones materiales de vida están limitadas. También se nota que los jóvenes tienen maneras de actuar, formas de agrupación y modos de ser y de vestir particulares. Al parecer, somos testigos de que la actual juventud significa limitaciones en el desarrollo material, así como una multiplicación en la diversidad de los estilos de vida.

Durante mucho tiempo hablamos del desarrollo, no sólo económico o social, sino demográfico, de tal forma que expresiones tales como crecimiento económico, mejoramiento social, y aumento poblacional, no era sólo una escucha habitual, sino que eran ecos que murmuraban una mejora futura. En relación al aumento poblacional, se percibía de forma natural el aumento de nacimientos y con ello el incremento de jóvenes, actualmente el avance de la juventud está en riesgo, no sólo porque se perfila el cambio demográfico que conlleva un menor crecimiento de jóvenes, sino que el desenvolvimiento económico y social que conlleva la globalización limita el desarrollo laboral, educativo y familiar de los jóvenes.

Desde el punto de vista del sociólogo Sygmunt Bauman, la carrera de envejecimiento social europeo está avanzando, muchas de las sociedades de ese continente se mueven conforme a la llamada transición demográfica 
o cambio demográfico que implica sociedades en vías de envejecimiento, él opina que los jóvenes son quienes deben ocupar los distintos puestos que exige la división del trabajo global, paradójicamente, uno de los comportamientos de los jóvenes y adultos de esas sociedades, es la de no tener hijos, en consecuencia, en el futuro dependerían de los inmigrantes. Bauman afirma en una entrevista realizada en 2011 “... hoy hay 333 millones de europeos, pero con la medida actual de nacimientos (que sigue descendiendo en toda Europa) este número caerá hasta los 242 millones en los próximos cuarenta años. Para llenar ese vacío, serán necesarios al menos 30 millones de nuevos inmigrantes, de otro modo nuestra economía europea se hundirá junto con el estándar de vida que nos es tan precioso." (Bauman S., 2017)

Por su parte, las personas que alcanzan los 60 años y más, llegan a una etapa del desarrollo humano en la cual son llamados: viejos. Es una etapa en la cual se experimenta el desgaste del cuerpo y quizá enfermedades de carácter irreversible, o sea parte del desarrollo humano caracterizado como el envejecimiento, y después, seguramente, la muerte. Mientras tanto se realizan preguntas.

"En las próximas décadas, muchos países se caracterizarán por una proporción creciente de personas ancianas y muy ancianas (de más de 80 años) y una proporción cada vez menor, o que crece más despacio, de jóvenes. Es justo preguntar qué significa viejo en la primera mitad del siglo XXI, en especial en las sociedades dominadas por las industrias de servicios y la tecnología de la información y las telecomunicaciones. ¿Somos demasiado viejos para realizar trabajo significativo a los 63, 67 o 74 años? (Magnus, 2011)

\section{A MANERA DE CONCLUSIONES}

En el presente escrito nos es difícil formular conclusiones, porque las temáticas tratadas están abiertas a cambios y trasformaciones que quizá aún no percibimos, y por supuesto porque son temas sujetos a profundizar más estudio, reflexión y por supuesto discusión.

A manera de conclusiones, ofrecemos la comunicación y experiencia de un viejo sociólogo, así como el mensaje y testimonio de un anciano de la actualidad.

El sociólogo alemán, Norbert Elias, es autor de una singular conferencia titulada: El envejecimiento y la muerte algunos problemas sociológicos, misma que fue pronunciada en el Congreso Médico de Salzuflen en octubre de 1983, en esa época el autor contaba con 85 años de edad. Él inicia su ponencia de la siguiente manera: "Una experiencia que tuve en mi juventud ha cobrado cierta significación para mí ahora que soy más viejo. Asistía yo a la clase de un conocido médico en Cambridge. Lo vi entrar avanzando con dificultad, arrastrando los pies. Y me sorprendí preguntándome: «iPor qué arrastra los pies así? ¿Por qué no anda como una persona normal?» Enseguida me corregía mí mismo: « “No puede evitarlo -me dije-; es muy viejo»”. Él continúa señalando que los jóvenes y adultos "Saben que la gente mayor, incluso si conserva en gran parte su salud, suele tener dificultad para 
moverse del mismo modo que se mueve la gente sana en los restantes grupos de edad, excepción hecha de los niños muy pequeños. Saben que esto es así, pero lo saben de manera lejana. No pueden imaginarse la situación en las que sus propias piernas o su propio tronco no obedezcan los mandatos de su voluntad como de manera normal lo hacen." Más adelante señala "Pues la mayoría de la gente más joven carece de base en su experiencia para imaginar lo que se siente cuando el tejido muscular se va endureciendo gradualmente y quizá se vuelve adiposo, cuando el tejido conjuntivo aumenta mientras la renovación celular aminora su ritmo. Todos estos procesos fisiológicos son bien conocidos por la ciencia y en parte se entienden bien. Existe una muy amplia bibliografia sobre este tema. En cambio, se entiende mucho menos -y se toca con mucha menos frecuencia en la bibliografía científica- la experiencia misma de envejecer. Se trata de un asunto que relativamente se ha tratado poco." (Elías, 2009)

Ahora pasemos a revisar el testimonio de un viejo en la época actual, que por cierto y dentro de lo que cabe, finaliza con algo de optimismo.

"Estoy en mi habitación. Cada vez me cuesta más salir de casa. Comienzo a aislarme; envejezco. La ciudad crece; hay más vías rápidas, anchas avenidas difíciles de atravesar. Los automovilistas siempre tienen prisa, no entienden que camino, sí, pero no soy tan rápido. Afortunadamente los cláxones no me molestan: los oigo poco.

"La casa, claro, la construimos cuando jóvenes, no pensamos que el tiempo vuela. Ahora hay que ver cuántos arreglos habrá que hacer: barandales para las escaleras (tan lindas las escaleras voladas de los años cincuenta), las tinas de baño ahora necesitan soportes de apoyo y tapetes para no caer. Y las puertas deben cambiarse por unas más amplias, pues si nos visita alguien de la familia o un amigo, tienen dificultades para pasar por las puertas estrechas, sobre todo cuando traen un apoyo para poder caminar. Si quiero que me visiten, debo hacer pronto estos arreglos.

"La comunicación es menos personal; aunque es muy rápida con estos aparatos celulares, es difícil usarlos, con esas teclas tan pequeñas que mis dedos nudosos pulsan mal. Marco un número y me contesta alguien que no conozco. Hay tantos aparatos, con botones y tele comandos en casa, que bien pudiera no moverme de aquí, pero no, debo caminar, moverme, hacerme presente. Estoy vivo; quiero sentir el aire, la suave brisa matinal, el rumor de voces, pasos, gente a mí alrededor.

"Cierto, la vejez trae consigo cambios en mi cuerpo, sobre todo en los sentidos (visión, audición); la velocidad con que camino y la longitud de mis pasos disminuido, no tengo tan buen equilibrio. Pero ¡caramba!, no son motivos para aislarme." (Giovanni, 2011) 


\section{GLOBALIZATION AND DEMOGRAPHIC CHANGE}

\section{Abstract}

In the present paper entitled: Neoglobalization and Demographic Change, I raise the hypothesis that globalization evolves and reproduces inequalities, not only in developing nations, but in developed societies, projecting a new globalization species, which apparently intervenes not only in economic processes, but demographic, giving way to societies in situations of aging.

Keywords: Neoglobalization; demographic change; inequalities; young and old.

\section{BIBLIOGRAFIA}

BAUMAN, Z. (1997). La globalización. Consecuencias humanas. México: Fondo de Cultura Económica.

BECK, U. (1997). ¿Qué es la globalización? Falacias del globalismo respuestas a la globalización. Barcelona: Paidós.

ELÍAS, N. (2009). La soledad de los moribundos. México: Fondo de Cultura Económica.

GARCÍA, B. y. (2010). Los grandes problemas de México. Población. México: Colegio de México.

GIDDENS, A. (2000). Un mundo desbocado. Los efectos de la globalización en nuestras vidas. . Madrid: Taurus.

GIOVANNI, A. y. (2011). Muros y silencio. Envejecimiento. Ciencia, Academia Mexicana de las Ciencias.

HERNÁNDEZ, E. (2010). Diagnóstico Mundial de la juventud. México: Consejo Mundial de Población.

MAGNUS, G. (2011). La era del envejecimiento, como la demografía está transformando la economía global y nuestro mundo. México: Oceáno.

SAMIR, A. (1999). El capitalismo en la era de la globalización. España: Paidós.

Trabalho enviado em 12 de dezembro de 2017.

Aceito em 31 de janeiro de 2018. 